\title{
Dynamics of Goat Milk Production in Different Agro-Climatic Regions of Rajasthan
}

\author{
Vijay Kumar Baldodiya" and H.O. Sharma
}

Department of Agricultural Economics and Farm Management, College of Agriculture, Jawaharlal Nehru Krishi VishwaVidyalaya, Jabalpur-482004, Madhya Pradesh, India

*Corresponding author: vj071088@gmail.com

\begin{abstract}
The present investigation was conducted to make critical examination of change, variation and growth of milk production of goat in various agro-climactic zones during period of study (1998-2012). Goat milk production in Rajasthan increased to 1656 thousand tonnes (current year) from 726.33 thousand tonnes (base year) showed 127.99 per cent change with a variation of 31.87 per cent during the study period (1998-2012). The production of goat milk increased with 6.43 per cent per annum of growth rate significantly with a magnitude of 67.79 thousand tonnes per year. The maximum growth and magnitude of goat milk production increased significantly in Arid Western Plain (8.97 per cent) and growth rate of goat milk production was found highly significant in Arid Western Plains.
\end{abstract}

Keywords: Relative change, simple growth rate, milk production.

Agriculture and livestock are inter-dependent in our economy and livestock has been recognized as an important approach for sustained livelihood. Livestock contributes manure and draught power to agriculture while crop residues form the major source of feed to the livestock and this system of interdependence has sustained for centuries. Livestock are important sources of income and employment in rural sector. They help to meet the equity objective in rural development through their contribution to the cash income of small and marginal farmers and landless laborers.

India has largest livestock population in the world. The total livestock population of India makes up a huge number of 529.7 million and India stands first in Buffalo population (105.4 million), second in cattle (199 million), and goats (140 million), third in sheep (71.56 million), and fifth in poultry (648 million). In India Rajasthan stands first in goat population (21.50 million), followed by West Bengal (15.96million), and Utter Pradesh (14.79 million) according to livestock census 2007.

The goat is a versatile animal. It is known as the poor man's cow in India. Goat raising is one of the important agricultural enterprise particularly in rural parts of Rajasthan. They have tremendous ability to survive, and often thrive on sparse vegetation unsuitable for feeding of other livestock. Goats can be profitably raised with low investment under intensive and most extensive forms of nomadic grazing. The vast majority of this poorer section of rural population depends on goat rearing for income and certain amount of meat and milk for home consumption. Goat rearing requires low cost and hence suited to landless laborers, marginal farmers and industrial workers. In addition they form substantially useful fraction if their total farm income particularly, when crops fail due to drought and other adverse conditions.

The Rajasthan state has (11 per cent) livestock population of 56.67 million in India contributing nearly 2.56 per cent (152 thousand tons) of meat and 10.53 percent (13.94 million tons) of milk production to the country during year 2012-13. Rajasthan has first rank in population (15.30 per cent) and milk (34.30 per cent) production of goat in India, while 
6th rank in goat meat production (6.19 per cent) of the country. The present study has been formulated to know the trend and growth of goat milk different agro-climatic region of Rajasthan.

\section{MATERIAL AND METHODS}

Time series secondary data on milk production from 1998-99 to 2012-13 of goat were obtained from the data published by Directorate of Animal Husbandry and Fisheries, Government of Rajasthan.

\section{Analytical Framework}

\section{Growth rate analysis}

Simple Growth Rate was used to analyse the growth of milk production in different agro-climatic regions of Rajasthan.

\section{Analysis of ABSOLUTE and Relative Change}

Absolute change fails to depict a comparative change among the variable and therefore in addition to absolute change, relative change has also been estimate in this study.

\section{Standard deviation and coefficient of variance}

Coefficient of variation: This is a measure of relative dispersion for the purpose of comparing two or more statistical series. For comparing the variability present in them, coefficient of variation is used which is expressed in percentage term.

\section{RESULTS AND DISCUSSION}

\section{Change and Variation in Goat Milk Production}

Table 1 clearly indicates that Goat milk production in Rajasthan increased to 1656 thousand tonnes (current year) from 726.33 thousand tonnes (base year) showed 127.99 per cent change with a variation of 31.87 per cent during the study period (1998-2012).

The maximum relative change in goat milk production was found in Arid Western Plains (245.53 per cent), as compared to Internal Drainage Dry (217.08 per cent), Hyper Arid Partially Irrigated Zone (193.61 per cent), Semi-Arid Eastern Plain (78.23 per cent), Transitional Plain of Luni Basin (133.71 per cent), Sub Humid Southern Plain (65.40 per cent), Humid South Eastern Plain (127.35 per cent), Flood Prone Eastern Plain (50.72 per cent), Humid Southern Plains (130.61 per cent) and Irrigated North Western Plains (29.66 per cent). (Table 1)

The maximum variation in goat milk production in Rajasthan was found in Humid Southern Plains (49.06 per cent), followed by Arid Western Plains (48.46 per cent), Hyper Arid Partially Irrigated Zone (40.26 per cent), Internal Drainage Dry Zone (39.89 per cent), Humid South Eastern Plain (35.86 per cent), Transitional Plain of Luni Basin (35.51 per cent), Sub Humid Southern Plain (34.91 per cent), Flood Prone Eastern Plain (33.53 per cent), Irrigated North Western Plains (24.30 per cent) and Semi-Arid Eastern Plain (23.98 per cent) (Table 1).

The share of milk in total goat milk in Rajasthan was also observed in the base as well as in current year (Figure 1 and 2). In the base year the maximum share of goat milk was found in Semi-Arid Eastern Plains (16.94 per cent), followed by Sub Humid Southern Plain (12.39 per cent), Internal Drainage Dry (12.05 per cent), Humid South Eastern Plain (11.96 per cent), Flood Prone Eastern Plain (11.84 per cent), Arid Western Plain (11.02 per cent), Hyper Arid Partially Irrigated Zone (9.39 per cent), Transitional Plain of Luni Basin (7.63 per cent), Irrigated North Western Plains (5.06) and Humid Southern Plain (1.71 per cent). In the current year the maximum share of goat milk was found in Internal Drainage Dry Zone (17.93 per cent), followed by Arid Western Plains (17.87 per cent), Semi-Arid Eastern Plain (14.17 per cent), Hyper Arid Partially Irrigated Zone (12.94 per cent), Sub Humid Southern Plain (9.62 per cent), Transitional Plain of Luni Basin (8.37 per cent), Flood Prone Eastern Plain (8.37 per cent), Humid South Eastern Plain (5.35per cent), Irrigated North Western (3.10 per cent) and Humid Southern Plain (2.27 per cent).

In the state 72.53 per cent of goat milk production was accounted by the Internal Drainage Dry Zone, Arid Western Plains, Semi-Arid Eastern Plain, Hyper Arid Partially Irrigated Zone and Sub Humid Southern Plain. The share of goat milk in current year as compared to base year was increased in Internal Drainage Dry Zone (5.88 per cent), Arid Western Plains (6.85 per cent), Hyper Arid Partially Irrigated Zone (3.55 per cent), Transitional Plain of Luni Basin (0.74 per cent) and Humid Southern Plain (0.56 per cent) while decreased in Semi-Arid 
Table 1: Change and variation in goat milk production in different agro climatic regions in Rajasthan ('000' tonnes)

\begin{tabular}{ccccc}
\hline Regions & Base year & Current year & $\begin{array}{c}\text { Absolute change (Relative } \\
\text { change) (per cent) }\end{array}$ & $\begin{array}{c}\text { SD (CV) } \\
\text { (per cent) }\end{array}$ \\
\hline Arid Western Plains & 85.67 & 296.00 & $210.33(245.53)$ & $92.65(48.46)$ \\
Flood Prone Eastern Plains & 92.00 & 138.67 & $46.67(50.72)$ & $30.40(33.53)$ \\
Humid South Eastern Plain & 93.00 & 88.67 & $49.67(127.35)$ & $19.53(35.86)$ \\
Humid Southern Plains & 16.33 & 37.67 & $21.33(130.61)$ & $9.81(49.06)$ \\
Hyper Arid Partially Irrigated Zone & 73.00 & 214.33 & $141.33(193.61)$ & $50.05(40.26)$ \\
Internal Drainage Dry Zone & 93.67 & 297.00 & $203.33(217.08)$ & $72.04(39.89)$ \\
Semi-Arid Eastern Plain & 131.67 & 234.67 & $103.00(78.23)$ & $39.08(23.98)$ \\
Sub Humid Southern Plain & 96.33 & 159.33 & $63.00(65.40)$ & $35.61(34.91)$ \\
Transitional Plain of Luni Basin & 59.33 & 138.67 & $79.33(133.71)$ & $32.24(35.51)$ \\
Irrigated North Western Plains & 39.33 & 51.33 & $11.67(29.66)$ & $9.20(24.30)$ \\
Total & 726.33 & 1656.00 & $929.67(127.99)$ & $336.17(31.87)$ \\
\hline
\end{tabular}

** Figures in parenthesis showing percentage relative change (per cent) and coefficient of variance (per cent).

Eastern Plain (2.77 per cent), Sub Humid Southern Plain (2.77 per cent), Flood prone Eastern Plain (3.47 per cent), Humid South Eastern Plain (6.61 per cent) and Irrigated North Western Plain (1.96 per cent).

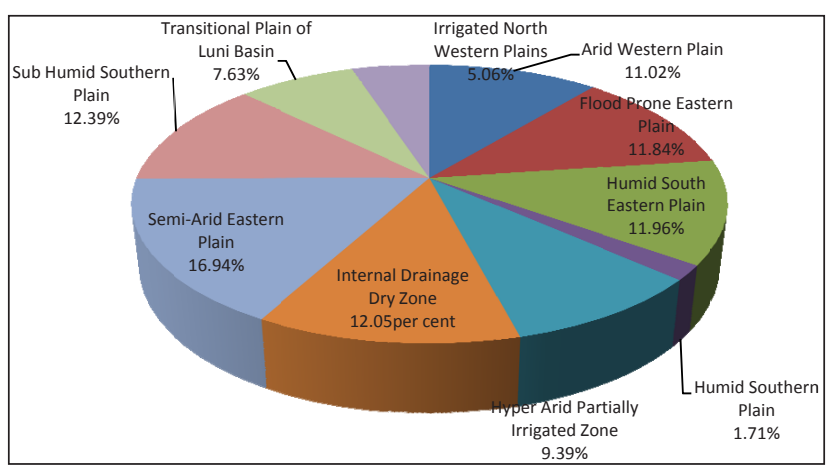

Fig. 1: Percentage share of goat milk production (726.33 lakh tonnes) in different agro climatic regions of Rajasthan during base year

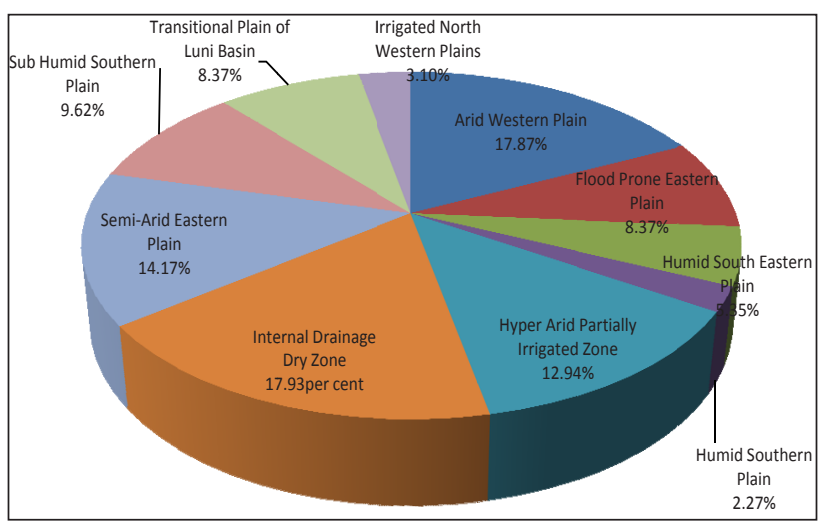

Fig. 2: Percentage share of goat milk production (1656 lakh tonnes) in different agro climatic regions of Rajasthan during current year

\section{Trend and growth in Goat Milk Production}

The production of goat milk showed increasing trend in state as well as all the agro climatic regions of Rajasthan as given in table 2 and Fig. 3. The production of goat milk increased significantly with 6.43 per cent per annum of growth rate with a magnitude of 67.79 thousand tonnes per year during the period of study.

Amongst all the agro climatic regions of Rajasthan the maximum growth of goat milk production was found in Arid Western Plains (8.97 per cent/ annum), followed by Internal Drainage Dry (8.47 per cent/ annum), Hyper Arid Partially Irrigated Zone (7.83 per cent / annum), Humid Southern Plains (7.40 per cent / annum), Humid South Eastern Plain (7.03 per cent /annum), Transitional Plain of Luni Basin (6.19 per cent /annum), Sub Humid Southern Plain (5.10 per cent / annum), Semi-Arid Eastern Plain (4.04 per cent / annum), Flood Prone Eastern Plains (2.91 per cent / annum) and Irrigated North Western Plain (0.71 per cent / annum) (Table 2).

The growth rate of goat milk production was found highly significant in Arid Western Plains, Hyper Arid partially Irrigated Zone and Transitional Plain of Luni Basin while found significant in Humid Southern Plains, Semi-Arid Eastern Plain and Sub Humid Southern Plain. The growth of goat milk population was found non-significant in Flood Prone Eastern Plains and Irrigated Western Plain (Table 2). 
Table 2: Trend and growth in goat milk production in different agro climatic regions in Rajasthan

\begin{tabular}{cccc}
\hline Regions & Trend $\mathbf{( b )}$ & S.E of b & SGR (per cent) \\
\hline Arid Western Plains & $17.16^{* * *}$ & 3.22 & 8.97 \\
Flood Prone Eastern Plains & 2.64 & 1.74 & 2.91 \\
Humid South Eastern Plain & 3.83 & 0.58 & 7.03 \\
Humid Southern Plains & $1.48^{* * *}$ & 0.45 & 7.40 \\
Hyper Arid Partially Irrigated Zone & $9.74^{* * *}$ & 1.53 & 7.83 \\
Internal Drainage Dry Zone & 15.29 & 1.41 & 8.47 \\
Semi-Arid Eastern Plain & $6.58^{* * *}$ & 1.60 & 4.04 \\
Sub Humid Southern Plain & $5.20^{* *}$ & 1.68 & 5.10 \\
Transitional Plain of Luni Basin & $5.62^{* * *}$ & 1.25 & 6.19 \\
Irrigated North Western Plains & 0.27 & 0.57 & 0.71 \\
Total & $67.79^{* * *}$ & 9.00 & 6.43 \\
\hline
\end{tabular}

*** and ** Significant at 1 and 5 per cent level.

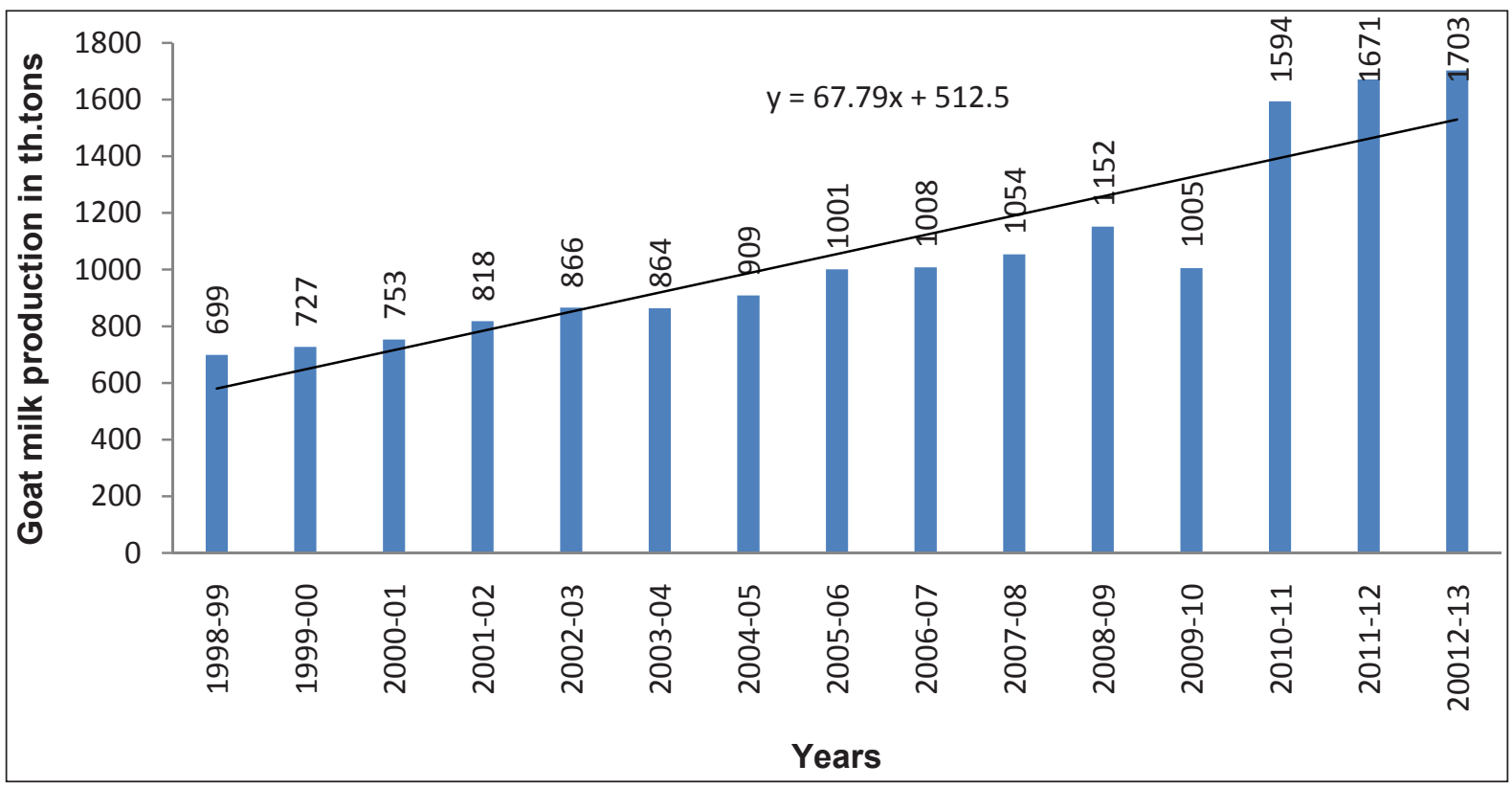

Fig. 3: Trend in goat milk production in Rajasthan during 1998 to 2012

These results were also confirmed by Tripathi et al. (1994) and Singh et al. (2008) that the production of goat milk increased over the year in different location in India.

\section{CONCLUSION}

It can be concluded from the above study that the production of goat milk showed increasing trend in state as well as all the agro climatic regions of Rajasthan. Hence, there will also a possibility to increase the production of goat milk with a magnitude of 67.79 thousand tonnes per year of milk with an annual growth rate of about 7 per cent per annum. The milk production growth varies from
8.97 per cent Arid Western Plain to 0.71 per cent in Irrigated North Western Plains.

\section{REFERENCES}

Anonymous, 2012. Annual Report of Department of Animal Husbandry, Dairying \& Fisheries. Ministry of Agriculture, Government of India.

Singh, M.K. Rai, B. Singh, P. and Singh, P.K. 2008. Goat production status in different agroclimatic regions of India. Indian Journal of Small Ruminants, 14(1): 48-70.

Tripathi, M.K. Singhal, K.K. and Mishra, R.K. 1994. Livestock population and production growth in India. Indian Dairyman, 46(6): 337-339. 